\title{
Evergreening: A Common Practice to Protect New Drugs
}

\section{Citation}

Katherine Gaudry, Evergreening: A Common Practice to Protect New Drugs (May 2011).

\section{Permanent link}

http://nrs.harvard.edu/urn-3:HUL.InstRepos:8965556

\section{Terms of Use}

This article was downloaded from Harvard University's DASH repository, and is made available under the terms and conditions applicable to Other Posted Material, as set forth at http:// nrs.harvard.edu/urn-3:HUL.InstRepos:dash.current.terms-of-use\#LAA

\section{Share Your Story}

The Harvard community has made this article openly available. Please share how this access benefits you. Submit a story.

Accessibility 


\title{
Evergreening: A Common Practice to Protect New Drugs
}

\author{
Katherine S. Gaudry \\ Harvard Law School \\ Class of 2011
}

Submission Date: May 30, 2011 


\begin{abstract}
Exclusivity periods serve as an incentive for pharmaceutical companies to engage in the costly and risky activities underlying drug discovery and development. Patents offer one form of exclusivity. Other exclusivities are awarded upon receiving specific types of approvals from the Food and Drug Administration. Here, I present data related to the exclusivity periods associated with all new-drug applications approved between 2000 and 2010. Recently approved drugs have fewer exclusivity periods. The duration between a drug's approval and the expiration of its final exclusivity period is also shorter for recently approved drugs. This data suggests that companies frequently engage in evergreening strategies, through which exclusivity periods are gradually accrued beyond drugs' approval date. Thus, companies' total exclusivity time periods may be extended. Though later-granted exclusivity periods may be of more limited scope than earlier obtained exclusivities, they may nonetheless increase total drug-associated profits. The potential widespread occurrence of evergreening suggests that this exclusivity-extending opportunity itself contributes to the incentives that justify pharmaceutical companies' new-drug investments.
\end{abstract}




\section{TABLE OF CONTENTS}

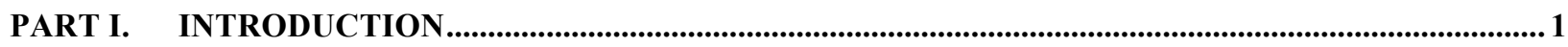

PART II. EXCLUSIVITY PERIODS AVAILABLE TO PHARMACEUTICAL COMPANIES ................... 4

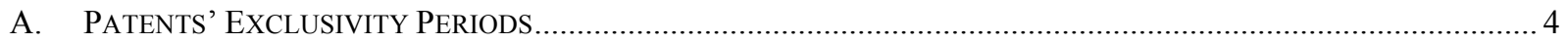

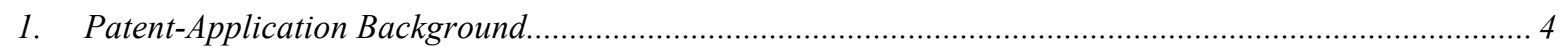

2. Term of Patent Protection - Approximately 20 Years from Filing.............................................................. 6

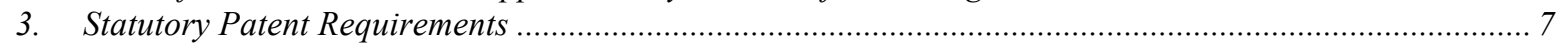

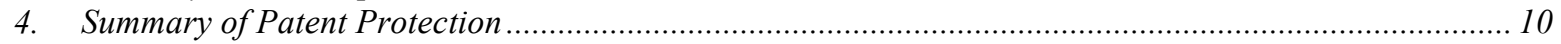

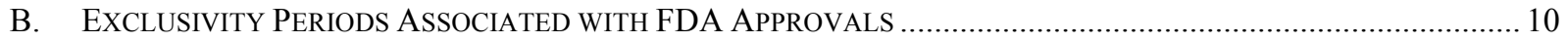

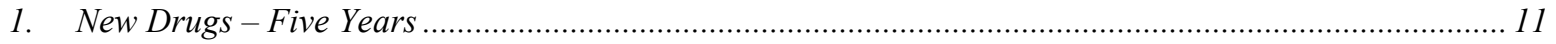

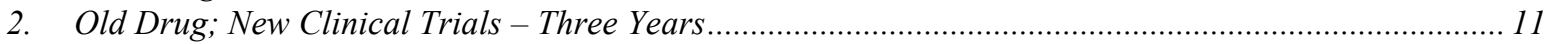

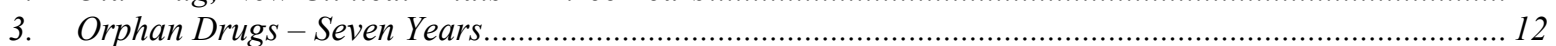

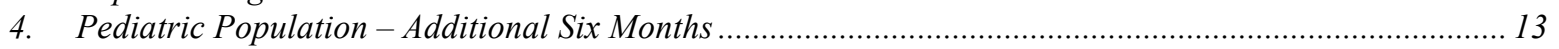

PART III. DATA OF EXCLUSIVITY PERIODS ASSOCIATED WITH NDAS ............................................. 13

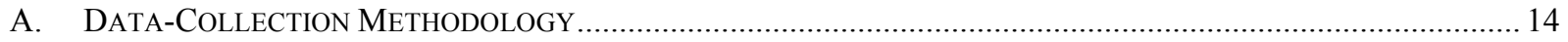

B. RECENT NDAS ARE ASSOCIATED WITH FEWER AND SHORTER EXCLUSIVITY PERIODS ……......................... 15

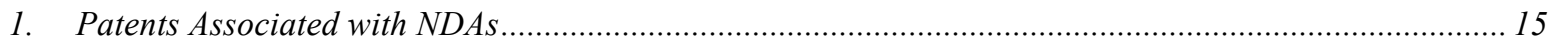

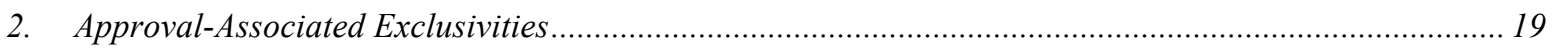

PART IV. INTERPRETATION: DYNAMIC PURSUIT OF EXCLUSIVITY PERIODS................................ 21

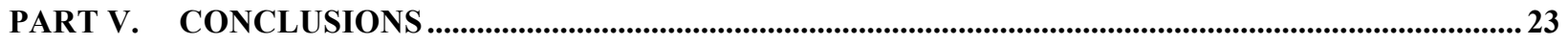




\section{Part I. Introduction}

With ailments and drug resistance abound, patients depend on pharmaceutical companies to discover and market new drugs. Discovery of such new drugs may be rewarded with substantial profits. However, pharmaceutical companies' profits must be analyzed in view of the costs and risks associated with their research programs.

First, discovery of a new drug is a very risky venture. It is estimated that out of 5,00010,000 drugs screened by companies, 250 enter pre-clinical testing. 5 drugs then enter clinical testing and 1 drug is approved. ${ }^{1}$ Thus, only about $0.02 \%$ of all drugs screened are ever approved by the FDA. Of those drugs approved, it is estimated that most drugs yield profits insufficient to cover the costs of the research and development associated with drug-discovery projects. ${ }^{2}$

Second, pharmaceutical research and development is expensive. In 2006, the average cost of drug development was estimated to be as high as $\$ 1.3$ billion. ${ }^{3}$ In addition to direct monetary costs, companies must also endure a substantial temporal cost. A pharmaceutical company must undergo preclinical testing and clinical testing in order for a new drug to be approved by the Food and Drug Administration (FDA). The total testing and approval time has been increasing since the 1960s, from 8.1 years in 1963-1969 to 14.2 years in 1990-1999. ${ }^{4}$ Of the 14.2 -year time investment in the $1990 \mathrm{~s}, 11.9$ years of that period was attributed to the costly preclinical and clinical testing (with 1.8 years attributed to approval time). ${ }^{5}$ Not only does the testing and correspondence with the FDA cost a pharmaceutical company money, but their attention and

\footnotetext{
${ }^{1}$ Kate, Kerry Ten, and Sarah A. Laird. (1999). The Commercial Use of Biodiversity: Access to Genetic Resources and Benefit-Sharing. London: Earthscan.

${ }^{2}$ Henry Grabowski and John Vernon, A New Look at the Returns and Risks to Pharmaceutical R\&D, Management Science 36, 804-21 (1990).

${ }^{3}$ Joseph A. DiMasi, and Henry G. Grabowski, The Cost of Biopharmaceutical R\&D: Is Biotech Different? Managerial and Decision Economics 28, 469-79 (2007).

${ }^{4}$ Joseph A. DiMasi, New Drug Development in U.S. 1963-1999, Clinical Pharmacology \& Therapeutics 69, 286-96 (2001).

${ }^{5}$ Id.
} 
involvement in the process precludes them from partaking in other projects that may yield a profit.

Upon receiving FDA approval of a drug, a pharmaceutical company may wish to set the price of its drug substantially higher than its manufacturing and distribution costs. This price inflation may help pay for the research, development, and approval processes associated with the drug. However, a generic manufacturer may not have the same motivations for inflating its price. Not only did it not have to undergo the costly research and development, but also, the FDA may approve a generic drug through a quicker and cheaper process. ${ }^{6}$ Thus, a generic drug with a price only slightly higher than its manufacturing and distribution costs may be sufficient to provide a generic manufacturer with a profit. If a generic product enters the market, a name-brand manufacturer may choose to lower its price in an effort to avoid losing its market share to a manufacturer of the generic drug. However, the lower price may be insufficient to fully compensate the name-brand manufacturer for its investments.

The government offers several exclusivity periods in an effort to provide companies with the opportunity to recover their investments in new products. Specifically, a pharmaceutical company may apply for and receive one or more patents that can prevent other companies from manufacturing or selling a similar or identical drug. Additionally, under the Drug Price Competition and Patent Restoration Act (also referred to as the "Hatch-Waxman Act"), a company may be awarded exclusivity periods for receiving specific types of approvals. These exclusivity periods can allow pharmaceutical companies to fully capture a market and control its product pricing. Therefore, exclusivity periods offer profit-potential opportunities to pharmaceutical companies.

\footnotetext{
${ }^{6}$ See 21 C.F.R. § 355(j) (2010).
} 
Under the practice of "evergreening", a company may attempt to extend its total monopoly by securing a number of monopolies - each beginning and ending at different times. For example, a company may file a first patent application claiming a new chemical compound. Several years later, the company may file a second patent application claiming a use of the compound to treat a condition. Later yet, the company may file a third patent application claiming a particular formulation of the compound. The term of a patent is generally 20 years from filing ${ }^{7}$, and so a patent arising from third patent application would likely expire years after the expiration of a patent arising from the first patent application. Though the latter part of the monopoly would likely cover a narrower concept, the protection may be sufficient to deter competitors from attempting to design-around the patent. While evergreening is frequently discussed in the context of patent law, a similar strategy could be employed based on the exclusivity periods associated with FDA approvals.

The evergreening strategy raises concerns that drug prices are kept at high levels for extended periods of time, thereby harming patients' access to drugs. However, the potential extended monopoly may increase the incentives available to pharmaceutical companies to identify and develop new drugs. ${ }^{8}$ Identifying the prevalence of evergreening may thus provide an indication as to whether evergreening itself is serving as an incentive for new-drug research. Presumably, a company would spend the time and money on securing additional exclusivity periods only if these added terms were valuable to the company.

Part II of this paper identifies the specific exclusivity periods available to drug companies (i.e., via patent statutes and the Hatch-Waxman Act). Part III presents global results identifying the exclusivity periods actually secured by pharmaceutical companies. Part IV presents a case

\footnotetext{
${ }^{7} 35$ U.S.C. § 154 (2010).
} 
study of the exclusivity periods associated with a particular new drug application. In Part V, I discuss the interpretations and implications of the results.

\section{Part II. Exclusivity Periods Available to Pharmaceutical Companies}

Two types of exclusivity periods are available to pharmaceutical companies. First, a company may file one or more patent application, each of which may issue into a patent. Each patent includes "claims" that define the scope of the invention. If others attempt to sell a drug in a manner that would infringe a company's patent claims, the company can file a lawsuit to prevent or to stop the sale of the drug. Second, a company may receive an exclusivity period by virtue of receiving specific types of approval of a drug through the FDA. The existence and durations of the periods depend on the particular approval received. Below, each type of exclusivity period is discussed in further detail.

\section{A. $\quad$ Patents' Exclusivity Periods}

\section{Patent-Application Background}

If a company believes that a method or product that it has developed is inventive, it may choose to file one or more patent applications with the United States Patent and Trademark Office (PTO). The application must include one or more claims setting forth the subject matter which the patent applicant regards as the invention. ${ }^{9}$ Claims may be directed to, e.g., a new drug or combination of drugs, a formulation of a drug, a method of using a drug, or a method of making a drug.

\footnotetext{
${ }^{8}$ F.R. Schrerer, The Link Between Gross Profitability And Pharmaceutical R\&D Spending, Health Affairs, 20: 21620 (2001).

${ }^{9} 35$ U.S.C. $\S 112(2010)$.
} 
Claims may be broad (e.g., covering a class of compounds) or narrow (e.g., covering specific ingredients and quantities in a composition). While it may be more difficult to show that broad claims are valid (as discussed below), they cover many potential design-arounds that may be envisioned by against generic competition. Claims may also be of different "types", which are directed to different concepts (e.g., methods of use versus formulations) and thus of different scopes. Thus, companies frequently develop a patent portfolio, whereby they pursue many claims, each varying in scope and type.

The PTO assigns each patent application to an examiner, who reviews the application and claims and searches for relevant prior art. ${ }^{10}$ The examiner frequently rejects the application, finding that the claims do not meet one or more statutory requirements (briefly described below). ${ }^{11}$ The patent applicant can respond to the rejection by traversing the rejection and/or amending the claims. ${ }^{12}$ Such communications between the examiner and applicant can continue for several rounds. Eventually, the application is either allowed by the examiner (such that it issues as a patent) or abandoned by the applicant.

Once a patent has issued, other entities are not allowed to make, use, offer to sell, or sell what is set forth in the claim. ${ }^{13}$ If another company does, the patentee can then "enforce" its patent by filing suit. The patentee must show that the other company has infringed its patent (by performing one of the above-listed acts) and that the patent is valid. At that point, the infringer is liable to the patentee. ${ }^{14}$

\footnotetext{
${ }^{10}$ United States Patent and Trademark Office, U.S. Dep't of Commerce, Manual of Patent Examining Procedure 903.08(b) (8th ed., 8th rev. 2010) [hereinafter MPEP].

${ }^{11}$ MPEP $§ 2660$.

${ }^{12}$ MPEP $§ 714$; MPEP $§ 2600$.

${ }^{13} 35$ U.S.C. $\$ 271$ (2010).

${ }^{14} 35$ U.S.C. $§ 271(2010)$.
} 


\section{Term of Patent Protection - Approximately 20 Years from Filing}

Generally, a patent's term extends from the date on which the patent issues to the date that is 20 years from the date that the application was filed. ${ }^{15}$ However, some situations give rise to different effective terms.

For example, if a reference application (issuing as a reference patent) claims priority to a previously filed application, then the expiration of a term of the reference patent's term is typically assessed with respect to the filing date of the priority document. ${ }^{16}$ That is, if Application X (filed on 1/1/2003) claimed priority to Application Y (filed on 1/1/2001), the patent would expire 20 years from the filing date of Application Y (on 1/1/2021). This situation may occur when a continuation application is filed claiming priority to another application. A continuation application is one: (1) in which the same invention is claimed as in a first application; (2) that is filed before the first application becomes abandoned or patented; and (3) that shares at least one inventor with the inventors named in the first application. ${ }^{17}$

A company may choose to file a continuation application for a number of reasons. One reason is that it allows the company to pursue claim sets directed towards different aspects of the invention. Even after a first application issues, the company may continue to tailor claims in continuation applications based on features of its product that it then sees as most valuable or worthy of protection. This is especially useful if the first application was filed before a pharmaceutical company began or completed its clinical trials and/or identified the product to be marketed. Thus, continuation applications allow claiming flexibility. However, these

\footnotetext{
${ }^{15} 35$ U.S.C. $\S 154$ (2010).

${ }^{16}$ MPEP $§ 2701$. This discussion relates only to non-provisional applications claiming priority to a non-provisional application. For more details about provisional applications, see 35 U.S.C. $§ 111(b)$ and 35 U.S.C. $§ 119$ (2010)

${ }^{17}$ MPEP $\S 201.07$.
} 
applications do not allow a company to extend the exclusivity awarded for the invention beyond that which would be secured by a single application.

\section{Statutory Patent Requirements}

Because patent-term expirations are tied to the date that an application was filed, it would appear to be advantageous to delay filing as long as possible. Further, because patent terms of continuation applications expire based on the filing date of the "parent" application, from which priority was claimed, it would seem to be advantageous to file new patent applications rather than claiming priority to a parent application. However, such strategies may fail due to the statutory patent requirements.

\section{a. Novelty and Non-Obviousness}

Two important patent requirements are that the claimed subject matter must be novel and non-obvious to one skilled in the art at the time of the invention. ${ }^{18}$ After an application is filed, an examiner will conduct a search of the prior art in an effort to determine whether one or more references disclose information that would anticipate or render obvious the claimed subject matter. ${ }^{19}$ This search is not restricted to patents and can include, e.g., scholarly publications. ${ }^{20}$ Thus, for example, an obviousness issue may be raised if an academic lab published data relating to the effectiveness of a set of compounds in treating an animal-model of a disease or slowing the growth of cultured cell. Further, even a publication merely expressing a hypothesis that a

\footnotetext{
${ }^{18} 35$ U.S.C. $\S \S 102-103(2010)$.

${ }^{19}$ MPEP $\S 904$.

${ }^{20} 35$ U.S.C. $\S 102$ (2010).
} 
drug would effectively treat a disease may be enough to preclude specific types of patent protections. $^{21}$

The query about what was known or obvious is conducted based on disclosures available at the time that the application was filed. Thus, later-filed applications will be subject to additional references that may disclose or make obvious key aspects of a pharmaceutical company's invention. Earlier filed applications or applications claiming priority to earlier filed applications (e.g., continuation applications) can avoid consideration of recent disclosures with respect to patentability issues.

Even a company's own disclosures (e.g., through published documents, web sites, or even conversations) can be used against the company to show that its later-claimed invention was anticipated or obvious. ${ }^{22}$ Thus, for example, if the company announces promising laboratory results in an effort to promote investor confidence, this disclosure may preclude the company from later receiving a patent on the concept. In the United States, inventors have one year from the date of a public disclosure to file a patent application. Otherwise, the disclosure may be cited against them in anticipation or obviousness rejections. ${ }^{23}$ This one-year grace period is not available in most other countries. Thus, companies seeking international protection of a drug may have additional incentives to file patent applications before any key information is disclosed through their participation in clinical trials or public disclosures required in the drug-approval process.

\footnotetext{
${ }^{21}$ Benjamin N. Roin, Unpatentable Drugs and the Standards of Patentability, 87 Texas L. Rev. 503, 517-21 (2009).

2235 U.S.C. $§ 102$ (b) (2010).

${ }^{23} \mathrm{Id}$.
} 


\section{b. Double Patenting}

Double patenting is a doctrine created to prevent inventors from unjustifiably extending exclusivity beyond the term of an initial patent. ${ }^{24}$ Under this doctrine, claims can be rejected if they are directed to "the same invention" as an issued patent or if they are directed to a subject matter not patentably distinct from claims in an issued patent. ${ }^{25}$ Provisional double-patenting rejections may reject a second application over claims in a first non-issued patent application, being contingent upon the first application issuing as a patent. ${ }^{26}$ Double-patenting rejections require: (1) at least one common inventor between the application and patent; or (2) specific types of common assignment or ownership between the application and patent. ${ }^{27}$

Recall that above I explained that one advantage of a continuation application is that it allows a company to continually tailor their claims to important concepts and protect various features of a drug. However, the disadvantage was that the continuation's patent term was limited based on the filing date of a parent application. An alternative filing strategy is to file a new application, not claiming priority to the parent application. This may be an appropriate action, particularly if there are new inventive features related to the drug that were not disclosed in the parent application. However, if the company is attempting to claim subject matter that is the same or is obvious as that claimed the parent application, the double-patenting doctrine would prevent the company from receiving two independent patents. Anticipation and obviousness rejections under 35 U.S.C. $\S \S 102-103$ may also be applied in this situation,

\footnotetext{
${ }^{24}$ MPEP $§ 800$.

${ }^{25} \mathrm{Id}$.

${ }^{26} \mathrm{Id}$.

${ }^{27}$ Id.
} 
depending on, e.g., publication dates, filing dates, and inventor lists associated with the application and patent. ${ }^{28}$

\section{Summary of Patent Protection}

In sum, patent protection typically extends 20 years from the filing date of an application. While later-filed applications allow companies' terms to extend to a later date, they are also accompanied by an increased risk that their own or others' disclosures will prevent them from receiving any patent protection at all.

After an initial application is filed, companies may continue to file additional applications. Applications pertaining to new concepts can lead to extended exclusivity terms. However, the patent term associated with subsequent applications claiming the subject matter similar to that claimed in an earlier application will be tied to the filing date of the earlier application. A new, independent term may be obtained if the company shows that the later-filed patent application includes claims that are non-obvious and novel over those in previous applications. Such a strategy may require the company to pursue narrower claims, which would offer weaker protection against generic competition. Nevertheless, even a narrow protection may be valuable, e.g., by preventing generic manufacturers from selling the particular composition shown to be safe and effective by the pharmaceutical company's clinical trials.

\section{B. Exclusivity Periods Associated with FDA Approvals}

The Hatch-Waxman Act outlines exclusivity periods are available to companies who receive specific types of approvals through the FDA. ${ }^{29}$ The length of the exclusivity period 
depends on the approval received. Immediately below, I describe the primary types of exclusivity periods and identify their durations. The identified durations do not account for additional effective exclusivity terms resulting from patent litigations or from the postexclusivity time that it takes the FDA to approve an application. ${ }^{30}$

\section{New Drugs - Five Years}

If a company receives approval of a new active ingredient, the company receives five years of market exclusivity. ${ }^{31}$ During that time, the FDA cannot approve any other application seeking approval for a drug containing the active ingredient, unless the application includes independent clinical-trial data demonstrating the drug's safety and effectiveness. ${ }^{32}$

\section{Old Drug; New Clinical Trials - Three Years}

If a company receives approval of a drug including a previously approved active ingredient, it may nonetheless receive market exclusivity. Three years of exclusivity are granted if the application includes new clinical investigations (other than bioavailability studies) essential to the approval of the application and conducted or sponsored by the company. ${ }^{33}$ For example, new clinical trials may be required in instances in which a company is seeking approval of a

\footnotetext{
${ }^{29}$ The recently enacted the Biologics Price Competition and Innovation Act (BPCIA) also outlines exclusivity periods available to companies receiving approval of biologic drugs. This paper only considers the exclusivity periods associated with small-molecule drugs for two reasons. First, because the BPCIA was enacted in 2009, there is a very limited amount of data to analyze about exclusivity periods granted to companies sponsoring biologic-drug applications. Second, the BPCIA does not require that companies sponsoring a biologic-drug application publicly identify patents believed to cover sales of the drug. Meanwhile, for small-molecule drugs seeking approval under the Hatch-Waxman Act, patents claiming the drug or a method of using the drug must be identified in the application for approval. 21 U.S.C. $\S 355(\mathrm{~b})(1)(\mathrm{G})(2010)$. Thus, there is a direct way to analyze seemingly pertinent patents only for small-molecule drugs, not biologics. Because my objective is to analyze total exclusivity associated with drugs, it is important to obtain information identifying patents thought to protect the drug.

${ }^{30}$ But see Benjamin N. Roin, Unpatentable Drugs and the Standards of Patentability, 87 Texas L. Rev. 503. (2009), note 332.

${ }^{31} 21$ U.S.C. $\S 355(\mathrm{j})(5)(\mathrm{F})(\mathrm{ii})(2010)$.

${ }^{32} 21$ U.S.C. $\$ 355(\mathrm{c})(3)(\mathrm{E})(\mathrm{iii})(2010)$.
} 
new: dosage strength, dosage form, route of administration, indication, dosage schedule, patient population, or drug-release profile. ${ }^{34}$

Additionally, if a company that received a previous approval intends to effect an important change to the drug offered for sale (e.g., changing the drug's dosage), it must file a supplemental new drug application (sNDA). If an SNDA is approved and includes new clinical investigations (other than bioavailability studies) essential to the approval of the supplement, the company is awarded an additional three-year exclusivity period with respect to the new feature of the drug supported by the clinical trials. ${ }^{35}$

In both instances, the exclusivity period only protects the novel aspect tested in the clinical trials. ${ }^{36}$ For example, if the FDA approves an NDA for a drug administered at a first dosage and later approves an sNDA for a drug administered at a second dosage, an exclusivity period associated with the sNDA would not prevent a generic manufacturer from marketing the drug at the first dosage.

\section{Orphan Drugs - Seven Years}

If a drug is approved to treat a rare disease, the sponsoring company receives a sevenyear market exclusivity period under the Orphan Drug Act. ${ }^{37}$ During this time, the FDA cannot approve any generic applications or any clinical-trial applications under 35 U.S.C. § 355 (e.g., showing that the drug can effectively treat a new indication). ${ }^{38}$

\footnotetext{
${ }^{33} 21$ U.S.C. $\S 355(\mathrm{j})(5)(\mathrm{F})(\mathrm{iii})(2010)$.

${ }^{34}$ See Food and Drug Administration. Orange Book: Approved Drug Products with Therapeutic Equivalence Evaluations: Exclusivity Codes (2011), available at http://www.accessdata.fda.gov/scripts/cder/ob/docs/excltermsall.cfm.

${ }^{35} 21$ C.F.R. § 355(c)(3)(E)(iv) (2010).

${ }^{36}$ Rebecca S. Eisenberg, The Problem of New Uses, 5 Yale J. Health Pol'y L. \& Ethics, 717, 720 (2005).

${ }^{37} 21$ U.S.C. $\$ 360$ (aa)-(cc) (2010).

3821 U.S.C. $\$ 360(\mathrm{cc})(2010)$.
} 
While the seven-year exclusivity period is relatively long compared to other FDAassociated exclusivities, the market for an orphan drug is rather small. A rare disease eligible for the seven-year protection is any disease or condition which (A) affects less than 200,000 persons in the United States, or (B) affects more than 200,000 in the United States and for which there is no reasonable expectation that the cost of developing and making available in the United States a drug for such disease or condition will be recovered from sales in the United States of such drug. ${ }^{39}$

\section{Pediatric Population-Additional Six Months}

If the FDA requests that a drug company conduct pediatric clinical studies, and if the company completes the studies, the company may receive an additional six months of exclusivity. ${ }^{40}$ This may be added to any other exclusivity period pertaining to the drug: the fiveyear new-drug exclusivity period; the three-year new-clinical-trials exclusivity period; the sevenyear orphan-drug exclusivity period; or the exclusivity period secured by a patent listed by the company in its FDA application. ${ }^{41}$

\section{Part III. Data of Exclusivity Periods Associated with NDAs}

Identifying exclusivity periods granted to pharmaceutical companies may give an indication of which exclusivities serve as a reward (and thus an incentive) for pharmaceutical companies' research and development efforts. Thus, I gathered and analyzed data related to exclusivity periods associated with each small-molecule New Drug Application (NDA) filed in the past ten years.

\footnotetext{
3935 U.S.C. $\S 360 \mathrm{bb}(\mathrm{a})(2)$ (2010).

${ }^{40} 21$ U.S.C. $\S 355 \mathrm{a}(2010)$.
} 


\section{A. Data-Collection Methodology}

The FDA provides an online database of drug approval reports. The database can be searched for approvals within a particular month and year. ${ }^{42}$ Thus, I identified all NDA approvals from January 2000 to December 2010. I also requested and received data from the FDA identifying patents and approval-related exclusivities associated with these NDAs. ${ }^{43}$ Specifically, two data sets were provided.

A first FDA-provided data set related to patents publicly identified as being associated with approved NDAs. ${ }^{44}$ For each NDA, the data set identified any patents submitted by the sponsoring company to the FDA as claiming the drug product or method of use of the product. For each of these patents, the FDA provided the its patent expiration date and whether the patent was flagged with a substance flag and/or a product flag. A substance or product flag indicates that the drug sponsor submitted the patent as claiming the drug substance or product, respectively. ${ }^{45} \mathrm{~A}$ drug substance is "an active ingredient that is intended to furnish pharmacological activity or other direct effect in the diagnosis, cure, mitigation, treatment, or prevention of disease or to affect the structure or any function of the human body, but does not include intermediates use in the synthesis of such ingredient." ${ }^{, 46}$ A drug product is "a finished

\footnotetext{
${ }^{41} I d$.

${ }^{42}$ See Food and Drug Administration. Drug Approval Reports (2011), available at http://www.accessdata.fda.gov/scripts/cder/drugsatfda/index.cfm?fuseaction=Reports.ReportsMenu.

${ }^{43}$ Department of Health and Human Services, Letter to Katherine Gaudry. (Freedom of Information Act Request No. 2010-6543), 17 Jan. 2011.

${ }^{44}$ A company sponsoring an NDA must identify any patent claiming the drug or a method of using the reference drug that could reasonably be asserted. 21 U.S.C. $\$ 355(\mathrm{~b})(1)(\mathrm{G})$. Though the true applicability and validity of a patent may be difficult to assess, these listed patents were used as an estimate of patents protecting each approved drug.

${ }^{45}$ Food and Drug Administration. Electronic Orange Book (EOB) Query data files (2010), available at http:/www.fda.gov/drugs/informationondrugs/ucm129689.htm.

${ }^{46} 21$ C.F.R. $\S 314.3$ (2010).
} 
dosage form, for example, tablet, capsule, or solution, that contains a drug substance, generally, but not necessarily, in association with one or more other ingredients. ${ }^{\$ 47}$

A second FDA-provided data set included data identifying all exclusivities awarded based on receiving specific types of approvals. The data set identified the exclusivity code and the date upon which the awarded exclusivity would expire. Generally, there are 14 types of exclusivity codes: a new dosing schedule (D); a new indication (I); miscellaneous (M); a new combination (NC); a new chemical entity (NCE); a new dosage form (NDF); a new ester or salt of an active ingredient (NE); a new product (NP); a new patient population (NPP); a new route (NR); a new strength (NS); an orphan drug exclusivity (ODE); pediatric exclusivity (PED); and Rx to OTC switch or OTC use (RTO). ${ }^{48}$

Using NDA numbers, I wrote a computer program in MATLAB ${ }^{\circledR}$ to cross-reference applications between the lists. Thus, I could identify, for example, whether a particular NDA that was approved in a given year was associated with any patents or approval-related exclusivities. I wrote code to calculate the percentage of NDAs with particular characteristics (e.g., having one or more associated patents) and to identify and average variables (e.g., the number of associated patents) across NDAs. These calculations are described in additional detail below.

\section{B. Recent NDAs are Associated with Fewer and Shorter Exclusivity Periods \\ 1. Patents Associated with NDAs}

Under evergreening practices, a company would file patent applications across a long time span. Later-filed patents could provide for extended protection. Thus, if evergreening is

\footnotetext{
${ }^{47} I d$.

${ }^{48}$ Food and Drug Administration. Orange Book: Approved Drug Products with Therapeutic Evaluations: Exclusivity Codes (2010), available at http:/www.accessdata.fda.gov/scripts/cder/ob/docs/excltermsall.cfm.
} 
common, recently approved drugs should: (1) be associated with fewer patents, and (2) have a shorter total effective term across all associated patents.

Figure 1 shows data related to patent-associated exclusivity terms. As shown in Figure 1a (thick line), the probability of patent protection declines as a function of a drug's approval date. While $79 \%$ of applications approved in 2000 identified one or more pertinent patents, that percentage drops to $54 \%$ for applications approved in 2010 . Alone, this discrepancy may suggest that companies are delaying even initial filings of applications until their drugs have been approved. For example, a company may believe that it does not need patent protection during the early post-approval years (e.g., due to market-entry barriers and restrictions on generic-drug approvals).

However, Figure 1a suggests that companies are only delaying filing specific types of patent applications. For example, the percentage of NDAs having an associated patent with a drug-substance flag (thin, solid line) or a drug-product flag (dashed line) is approximately the same for older and newer drugs. ${ }^{49}$ Patent claims covering drug substances and drug products are likely very valuable: a generic manufacturer may apply for an abbreviated approval through the FDA and avoid replicating clinical trials if it shows that its drug has the same active ingredient as the reference drug and is bioequivalent to the reference drug. ${ }^{50}$ Thus, protection of the active ingredient and formulations that may affect the drug's bioequivalence can prevent generic market competition. It appears as though companies are not delaying filing patents having these important claims.

\footnotetext{
${ }^{49}$ As described above, a "drug-substance" patent includes a claim directed to an active ingredient in the approved product, and a "drug-product" patent includes a claim directed to a finished dosage form containing the drug substance.

${ }^{50} 21$ U.S.C. $\S 355(j)(2)(A)(i i)(2009)$.
} 

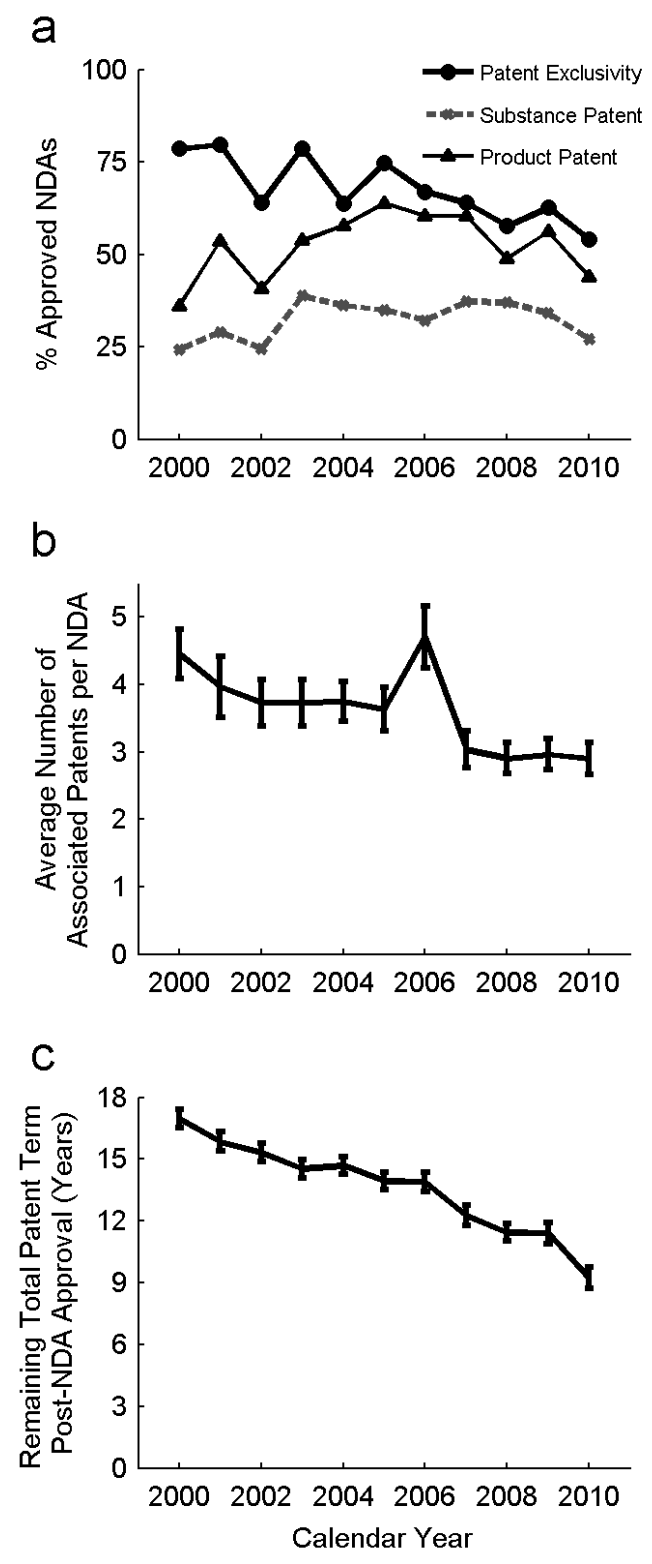

Figure 1: Characteristics of Patent Exclusivities Associated with NDAs. a: Probability of NDA-Associated Patents. The thick, solid line shows the percentage of all NDAs approved within the identified year for which one or more patents were identified under 21 CFR $\S 355(\mathrm{~b})(1) \mathrm{G})$ or $21 \mathrm{CFR} \S 355(\mathrm{c})(2)$ as claiming the NDA's drug or a method of using the drug. The thin, solid line shows the percentage of all NDAs approved within the identified year for which one or more identified patents claimed a drug product, as described in the text. The dashed line shows the percentage of all NDAs approved within the identified year for which one or more identified patents claimed a drug substance, as described in the text. $\boldsymbol{b}$ : Number of NDA-Associated Patents. For each NDA, I determined the total number of patents identified to the FDA as claiming the NDA's drug or a method of using the drug was determined. NDAs not associated with any patents were excluded, and the patent numbers were then averaged across the remaining applications approved within each year between 2000 and 2010. c: Maximum Post-Approval Remaining Patent Term. For each NDA, I determined the latest expiration date across all of the patents identified as claiming the NDA's drug or method of using the drug. The remaining total patent term was defined as the time between the NDA approval date and this expiration date. NDAs not associated with any patents were excluded, and the remaining terms were averaged across all applications approved within each year between 2000 and 2010. Error bars in (b) and (c) show the standard error of the mean. 
A monopoly-maximization strategy is further supported by analysis of the number of patents filed by pharmaceutical companies. For each year, I binned the NDAs approved in that year that were (or were subsequently) associated with at least one patent. I then calculated the average number of NDA-associated patents across all NDAs within the bin. Even though this analysis was restricted to patent-associated NDAs, the average number of patents per NDA is lower for recently approved drugs. (Figure 1b.) For example, an average of 4.5 patents were associated with 2000-approved NDAs compared to 2.9 patents for 2010-approved NDAs. This suggests that companies continue to pursue patents after the approval of their drug.

The smaller number of patents associated with recently approved NDAs does not necessarily indicate that these drugs are effectively protected by a shorter patent term. The “total" patent term combined across patents will depend on patents' filing dates and whether they claimed priority to a previous application, as described above. Thus, for each patent, I calculated the post-approval patent term as being the time from the NDA approval to the expiration of the patent. For each NDA associated with at least one patent, I identified the maximum postapproval patent term across all associated patents. Figure 1c shows the average of the maximum post-approval patent terms across all approvals within a given year for which at least one patent was associated with the approval. Thus, again, this analysis is not affected by the change in the percentage of NDAs having any associated patent protection. As shown, the maximum postapproval patent term also is declines across approval years: from 17.0 years for 2000 -approved NDAs to 9.2 years for 2010-approved NDAs. 


\section{Approval-Associated Exclusivities}

While evergreening is frequently discussed in the context of patents, the concept may also apply to other exclusivity periods as well. For example, as described above, a sponsoring company can receive exclusivity periods for receiving various types of drug approvals. A company may file an NDA seeking approval of some fundamental concepts early and, years later, file an sNDA (e.g., relating to a new patient population, new dosing regimen, etc.) - each resulting in an exclusivity period. Exclusivity periods associated with the initial approval and/or subsequent approvals could affect the company's strategy for filing NDAs, sNDAs, and/or patents. Thus, I examined how the FDA-associated exclusivity periods associated with recently approved drugs differed from those associated with older drugs.

As shown in Figure 2a, more recently approved drugs are less likely to be associated with an FDA-approval exclusivity period than are drugs with earlier approval dates. For example, $78 \%$ of NDAs approved in 2000 were granted an FDA-approval exclusivity period, compared to only $54 \%$ of 2010 -approved NDAs.

Comparing the number of exclusivity periods for recently approved drugs to older drugs may provide an indication as to whether companies were frequently obtaining post-approval exclusivities. Thus, for each year between 2000 and 2010, I identified NDAs approved in that year having at least one FDA-approval exclusivity period. I then determined the average number of FDA-approval exclusivity periods associated with these NDAs. For example, if a drug company was awarded a 5-year exclusivity period for successfully completing trials on a new chemical entity, and if it also performed pediatric studies warranting a 6-month extension of its exclusivity period, it would be associated with two codes. As shown in Figure 2b, even within this restricted data set, more recently approved drugs are associated with fewer FDA-approval 

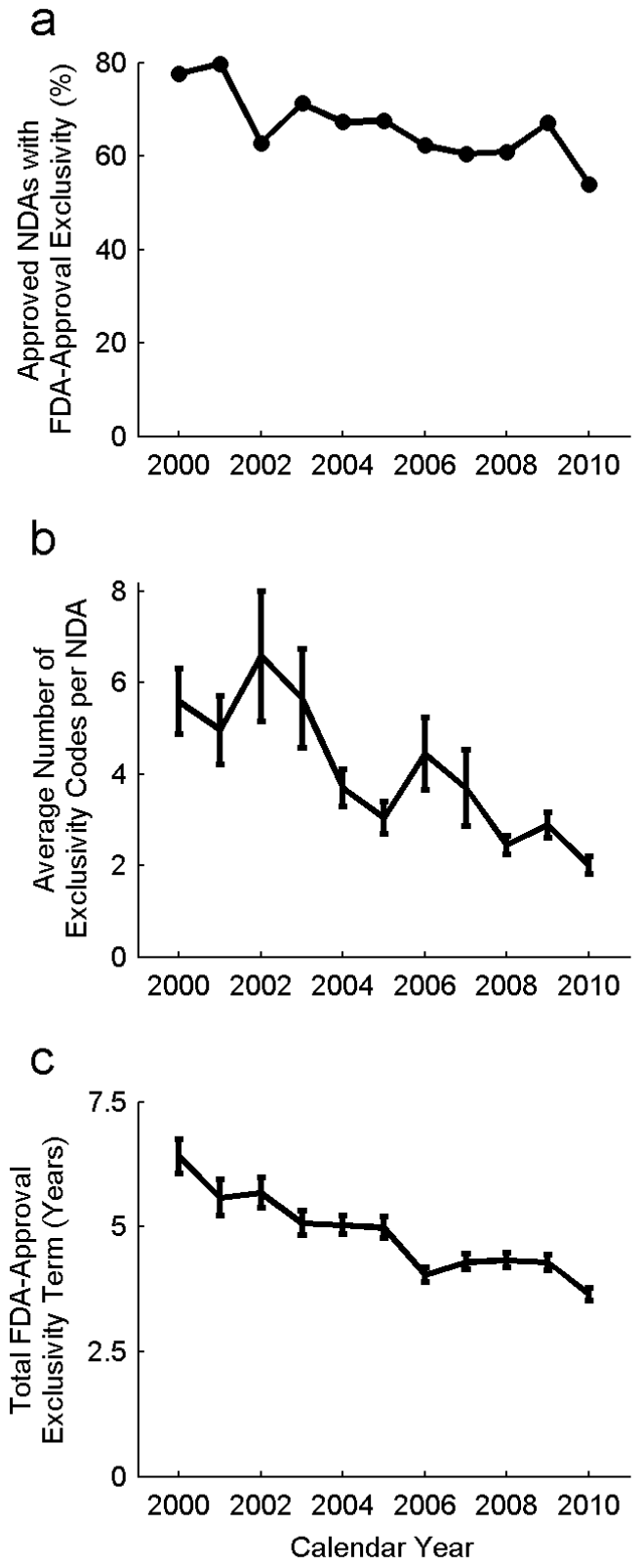

Figure 2: Characteristics of FDA-Approval Exclusivities Associated with NDAs. a: Probability of NDAAssociated FDA-Approval Exclusivity Periods. The graph shows the percentage of all NDAs approved within the identified year and having one or more FDA-approval exclusivity periods. $\boldsymbol{b}$ : Number of NDA-Associated FDAApproval Exclusivity Periods. For each NDA, I determined the total number of FDA-approval exclusivity periods associated with the NDA. NDAs not associated with any FDA-approval exclusivities were excluded, and the exclusivity-period numbers were then averaged across the remaining applications approved within each year between 2000 and 2010. c: Maximum Approval-Related Exclusivity Terms. For each NDA, I identified the expiration of each FDA-approval exclusivity period received. The maximum approval-related exclusivity term was defined as the time between an NDA's approval and the latest approval-related exclusivity-period expiration. NDAs not associated with any FDA-approval exclusivities were excluded, and the maximum approval-related exclusivity terms were averaged across all applications approved within each year between 2000 and 2010. Error bars in (b) and (c) show the standard error of the mean. 
exclusivity periods than previously approved drugs (5.6 periods for 2000-approved drugs versus 2.0 periods for 2010-approved drugs).

As with patents, the number of exclusivity periods is not itself indicative of the total exclusivity term. Rather, the total term may depend on the date that particular approvals were granted. Thus, I calculated a maximum FDA-approval exclusivity term as the time between the NDA's approval and the expiration of the final FDA-approval exclusivity term. Figure $2 \mathrm{c}$ shows that recently approved drugs are associated with shorter total terms than older drugs (6.4 years for 2000-approved drugs versus 3.6 years for 2010-approved drugs).

\section{Part IV. Interpretation: Dynamic Pursuit of Exclusivity Periods}

As shown in Figures 1-2, the following variables are lower for recently approved drugs: the overall percentage of NDAs associated with a patent- or approval-related exclusivity period; the number of patents associated with an NDA; the maximum post-approval patent term associated with an NDA; the number of approval-related exclusivity periods associated with an NDA; and the maximum post-approval exclusivity term associated with an NDA. This data is consistent with the evergreening theory outlined above. The theory would then predict that recently approved drugs would later be associated with more patents and FDA-associated exclusivity periods, thereby matching the older drugs in these respects.

Another possible interpretation of the data is that it reveals a dramatic change in patentand NDA/sNDA-filing strategies. For example, potentially, companies sponsoring older drugs immediately pursued many patents, and companies sponsoring newer drugs pursued fewer patents with no intention of pursuing more later. To examine this possibility, I considered 
specific data associated with an exemplary older NDA. Data showing that patents and/or sNDAs were pursued after the approval date would lend credence to the evergreening hypothesis.

NDA 021433 pertains to the drug fluticasone propionate, and the associated trade name is Flovent HFA. The NDA was approved on May 14, 2004. Three "NP" exclusivity codes were associated with the NDA, indicating that the NDA was an application for approval of a "new product." Three codes were assigned, each being associated with a different dosage strength. ${ }^{51}$ The expiration dates of each of these exclusivity periods were May 14, 2007 - three years after the NDA's approval date.

Approximately one year after the NDA approval, the sponsoring company submitted an sNDA requesting approval of the product to treat a new patient population (4-11 year olds). The sNDA was approved in February 2006, and additional three-year exclusivity periods were awarded to protect the use of the product (at each approved dosage) to treat the new population. Thus, in total, six exclusivity periods were awarded: three expiring in 2007 and three expiring in 2009 , though the latter three are of narrower scope than the former.

There were also 20 patents associated with this NDA. Two were issued in 1997, two in 2000 , three in 2001 , two in 2002 , three in 2003 , one in 2004 , two in 2005 , three in 2006 , one in 2008, and one in 2009. Recall that the approval date was May of 2004. Thus, eight of the patents (40\%) were issued after the NDA's approval. ${ }^{52}$ The latest patent expiration date among those patents issued before the NDA's approval is December 8,2018. Meanwhile, the latest patent expiration date among all associated patents is July 4, 2025.

The patent with the earliest expiration date (U.S. Patent No. 6,251,368) claims an aerosol formulation including a specific active ingredient and propellant in a particular weight ratio. The

\footnotetext{
${ }^{51}$ Food and Drug Administration. Drug Details (2011), available at http://www.accessdata.fda.gov/scripts/cder/drugsatfda/index.cfm?fuseaction=Search.DrugDetails.
} 
patent with the latest expiration date (U.S. Patent No. 7,500,444) claims a specific mechanical configuration of an actuation indicator (e.g., to count the number of doses administered by a device). Thus, it would appear as though it would be easier for a competitor to design-around the later patent as compared to the earlier patent. However, while I note that later-pursued exclusivity periods may be of smaller scope than initial periods, they may nonetheless provide some additional profit opportunities.

Of the 20 total patents, 12 of them claimed priority to at least one application that was eventually patented. Thus, not all of the patents were used as incremental extensions of an effective patent term. Rather, a substantial fraction served to add additional protection by merely having a new claiming strategy, different from that in the parent application.

\section{Part V. Conclusions}

The above-presented data suggests that companies frequently pursue exclusivity periods after receiving approval of an initial NDA. (Figures 1a, 1b, 2a and 2b.) In theory, some of the later-issued patents or later-filed sNDAs may not be part of an evergreening strategy. For example, a company may discover an advantageous drug formulation after receiving its initial approval. It may then file a patent application and an sNDA on this new formulation. I predict that, while such instances are not uncommon, conscious strategy explains most of the substantial and beneficial extended term associated with older drugs (Figures 1c and 2c).

Regardless of the cause of the post-approval patents and approvals, the data presented herein shows that simply characterizing drug-related monopolies using fixed terms would overlook the complete exclusivity profile associated with most drugs. Nevertheless, simply stating that this data shows that pharmaceutical companies, in effect, extend the exclusivity

\footnotetext{
${ }^{52}$ Overall, $28.6 \%$ of the patents associated with NDAs approved in 2000 were issued after the year 2000.
} 
periods associated with their drugs is also too simplistic. Such a characterization would ignore the time-dependent scope of the protection. (See the above analysis of NDA 021433.) Later-filed patents may need to be directed to narrow concepts in order to distinguish the claims from prior art and prior applications' claims. Further, an exclusivity awarded upon approval of an sNDA is limited to the novel feature approved.

In sum, the patent system and drug-approval system provide opportunities for companies to receive post-approval exclusivity periods. Companies frequently take advantage of these opportunities. Though the scope of the extended protection is usually narrower than that of initial exclusivity periods, it may nonetheless provide a pharmaceutical company with additional opportunities to profit from its drug. This incentive, along with the suggested prevalence of evergreening, may indicate that pharmaceutical companies' current research and development efforts are in part supported by the additional exclusivities offered by this approach. 